\title{
Fractal Loop Heat Pipe Performance Comparisons of a Soda Lime Glass and Compressed Carbon Foam Wick
}

\author{
David Myre ${ }^{1}$ \\ KDM Systems Incorporated, Chantilly, VA 20153, USA \\ Eric A. Silk ${ }^{2}$ \\ Cryogenics and Fluids Branch, NASA Goddard Space Flight Center, Greenbelt, MD., 20771, USA
}

This study compares heat flux performance of a Loop Heat Pipe (LHP) wick structure fabricated from compressed carbon foam with that of a wick structure fabricated from sintered soda lime glass. Each wick was used in an LHP containing a fractal based evaporator. The Fractal Loop Heat Pipe (FLHP) was designed and manufactured by Mikros Manufacturing Inc. The compressed carbon foam wick structure was manufactured by ERG Aerospace Inc., and machined to specifications comparable to that of the initial soda lime glass wick structure. Machining of the compressed foam as well as performance testing was conducted at the United States Naval Academy. Performance testing with the sintered soda lime glass wick structures was conducted at NASA Goddard Space Flight Center. Heat input for both wick structures was supplied via cartridge heaters mounted in a copper block. The copper heater block was placed in contact with the FLHP evaporator which had a circular cross-sectional area of $0.88 \mathrm{~cm}^{2}$. Twice distilled, deionized water was used as the working fluid in both sets of experiments. Thermal performance data was obtained for three different Condenser/Subcooler temperatures under degassed conditions. Both wicks demonstrated comparable heat flux performance with a maximum of $75 \mathrm{~W} / \mathrm{cm}^{2}$ observed for the soda lime glass wick and $70 \mathrm{~W} / \mathrm{cm}^{2}$ for the compressed carbon foam wick.

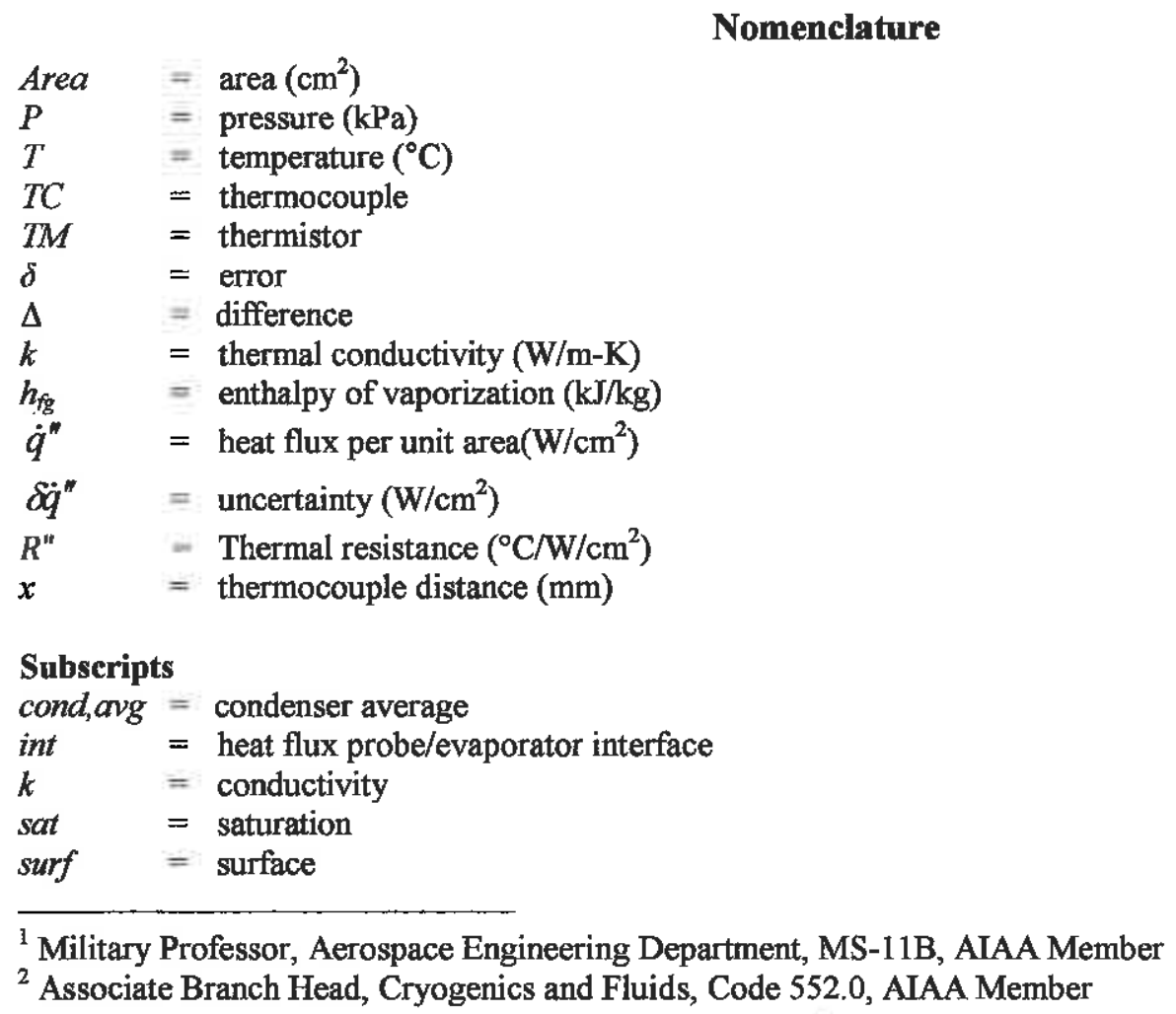




$\begin{array}{ll}T & =\text { temperature } \\ x & =\text { thermocouple distance }\end{array}$

\section{Introduction and Background}

Over the past twenty five years Loop Heat Pipes (LHPs) have successfully flown on several NASA Goddard Space Flight Center (GSFC) instruments such as GLAS (Geo-Laser Altimeter Science), EOS-AURA's TES (Tropospheric Emissions Spectrometer) and the SWIFT Gamma Ray Burst observatory. They have been established throughout the aerospace industry as reliable and robust heat acquisition/transport devices and are common to contemporaty thermal control systems (TCS) for spaceflight platforms. In this paper two wick materials are compared on the basis of heat transfer performance. A sintered fused silica glass wick representing a more typical LHP wick material is compared with a Carbon foam wick, a new entrant in the area of heat transfer materials. Carbon foam can be obtained commercially, manufactured with required porosity and easily machined to meet tight tolerances of evaporator structures for various applications. One of the motivations behind this study is to raise interest in the potential of these materials in research and development of Carbon foam wick based LHP's.

A significant review of LHP literature is available from many sources. There have been numerous studies performed to gain insight into the performance and operational characteristics of LHPs. Prior studies examining LHP performance and operational characteristics have investigated start-up [1-9], shutdown [1], steady state operation $[1-4,7,8]$, working fluid distribution $[2,3,10]$, and hysteresis phenomena $[1,2,11]$. Other topics investigated include analytical modeling $[1,12-15]$, temperature oscillations $[2,3,9]$, miniature (or small) LHP performance characteristics $[4,8,16]$, and spaceflight hardware performance reviews $[16,17]$. In addition, there have been several works written that provide an overview of LHP operational characteristics $[1,18,19]$. In each of the afore-mentioned studies, as well as throughout the comprehensive experimental LHP literature database, there have been several types of wick structure materials used to date. Standard wick materials used have included fine pore sintered metals such as Nickel $[4-6,8,9,14,16,20]$, Titanium [21,22] and Stainless Steel [23,24]. Alternate materials such as Porous Silicon [13], Polystyrene [25], Polyethylene [7,26] and Silica glass $[27,28,29]$ have also been used in LHPs as wick structures at a continually increasing rate. For a more complete review of relevant literature the authors recommend Silk and Myre $[28,29,30]$

Wu et al. [25] investigated LHP performance when using a polystyrene wick structure with Ammonia as the working fluid. The wick structure was tailor made (via a salt leaching method) for high porosity and low thermal conductivity. Several wicks having multiple porosities and pore radii were fabricated and tested. The wick structure which demonstrated the best thermal performance had a porosity of $80 \%$ and a pore radius of $5.9 \mu \mathrm{m}$. Tests performed with this wick structure demonstrated a transport capacity of $320 \mathrm{~W}$ and an overall thermal resistance of $0.234^{\circ} \mathrm{C} / \mathrm{W}$.

In the study by Nagano et al. [26], an experimental miniature LHP was used for heat transfer performance testing using a wick made of PTFE. Multiple PTFE wicks having pore sizes ranging between $0.8-2.2 \mu \mathrm{m}$ (porosity ranging $27 \%-50 \%$ ) were fabricated and tested for fluid transport capability, as well as effective thermal conductivity. The actual wick pore size selected for actual heat transfer performance tests was $1.2 \mu \mathrm{m}$. Using a PTFE wick of this pore size, the investigators successfully demonstrated start-up at input powers as low as $5 \mathrm{~W}$. In addition, the loop successfully transported $55 \mathrm{~W}$.

The initial FLHP study by Silk and Myre [28] investigated heat flux performance for the FLHP as a function of condenser/subcooler sink temperature combination using water as the working fluid. The wick structure was made of sintered fused silica glass with an average pore size (primary wick) ranging 8-10 $\mu \mathrm{m}$. The maximum heat flux performance observed was $75 \mathrm{~W} / \mathrm{cm}^{2}$ at a $5^{\circ} \mathrm{C}$ condenser temperature. Hysteresis testing showed negligible heat flux variation during the heating and cooling cycle. No failed start-ups occurred during testing. The follow-up study examining FLHP performance investigated heat flux as a function of evaporator to condenser orientation angle. The FLHP demonstrated successful start-ups in each test case and demonstrated a peak heat flux of $89 \mathrm{~W} / \mathrm{cm}^{2}$ with the condenser oriented 15 degree above the evaporator.

As a continuation of the initial FLHP validation performance study, Silk and Myre [31] investigated heat flux performance using a compressed Carbon foam wick The observed heat flux performance with the compressed Carbon foam wick was similar to that of the performance observed with the fused silica glass wick. The peak heat flux observed with the Carbon foam wick was reaching $\approx 70 \mathrm{~W} / \mathrm{cm}^{2}$ for the $15^{\circ} \mathrm{C}$ sink temperature case and a thermal resistance of $\approx 1.25^{\circ} \mathrm{C} / \mathrm{W} / \mathrm{cm}^{2}$ at moderate to high heat transport. In addition, similar to the silica glass wick structure tests, hysteresis effects were negligible. 
In the current study the authors compare the heat flux performance and thermal resistance characteristics of the two wick structures. This data offers the opportunity to compare the performance of two wick materials in which the LHP, the experimental set-up and wick geometry are identical. In both cases the wick structures demonstrate heat transfer performance that is exceptional for LHP's. The details of the experimental set-up, wick materials, wick fabrication and test conditions are provided in the following sections.

\section{Test Set-Up and Procedure}

The FLHP evaporator is atypical relative to the standard axial grooved evaporator configuration used in most LHPs. The evaporator structure (shown in Figure 1.) is made from multiple layers of photo-etched copper that create fractal like square passageways when laminated on top of one another (see Figs. 1a and 1b for example fractal stackup passageway). The multiple fractal layers are diffusion bonded together. The evaporator's cylindrical cross section is machined out of the multi-layer composite structure and integrated into the closed fluid loop (photo shown in Figure 2). The FLHP system (schematic shown in Figure 3) consists of an evaporator, vapor line, condenser, subcooler, liquid retum line and compensation chamber. The original primary and secondary wicks were both made of sintered spheres of soda lime glass. The heat flux probe and evaporator were made of oxygen free high thermal conductivity copper. The $\mathrm{CC}$, vapor line, liquid return line, condenser and subcooler were each made of stainless steel. Performance characteristics of this test apparatus with a wick structure consisting of sintered spheres of soda lime glass have been previously reported by Silk and Myre [28,29] for both the horizontal position and with orientation angles $\left(-30^{\circ}\right.$ to $\left.30^{\circ}\right)$ for the evaporator relative to the condenser's plane in a 1-g laboratory frame of reference.

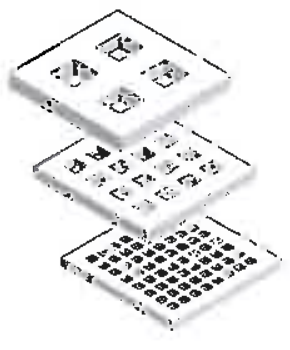

a)

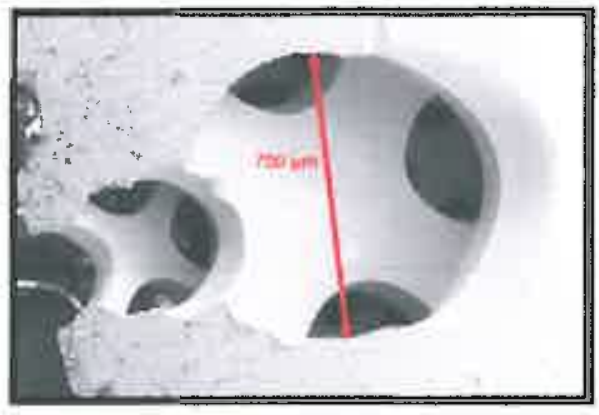

b)

Figure 1. Fractals; a) Stacked Fractal Layer Configuration, b) Example photograph of three layer fractal structure with circular through passages

Temperature measurements were taken using a combination of K-type thermocouples and $30 \mathrm{k} \Omega$ thermistors. The vapor line, condenser, subcooler and liquid return line were instrumented with thermistors (18 in total). The CC, heat input block and the evaporator were instrumented with five K-type thermocouples. A pressure transducer was also placed near the compensation chamber for determination of the FLHP's saturation conditions during loop operation.

Heat input was supplied to the FLHP evaporator using two $500 \mathrm{~W}$ cartridge heaters mounted inside the heater block (schematic shown in Fig. 3). Prior to the start of testing, the heater block was placed in intimate contact with the heat flux probe using Nusil CV-2946 as the Thermal Interface Material (TIM). Temperature measurements in the heat flux probe were performed using two thermocouples mounted in the heat flux probe's cylindrical cross section. These thermocouples had a separation distance of $10.0 \mathrm{~mm}$. Assuming steady state 1-D conduction through the heat flux probe, the heat flux was calculated using Fourier's Law with measured temperature values from thermocouple one and two ( $\mathrm{TC} 1$ and $\mathrm{TC} 2$ ). The interface surface temperature $\left(\mathrm{T}_{\mathrm{int}}\right)$ at the base of the heat flux probe (immediately adjacent to the evaporator housing) was determined by extrapolation using Fourier's Law with TC1, TC2 and measured distance along the probe to the interface. 


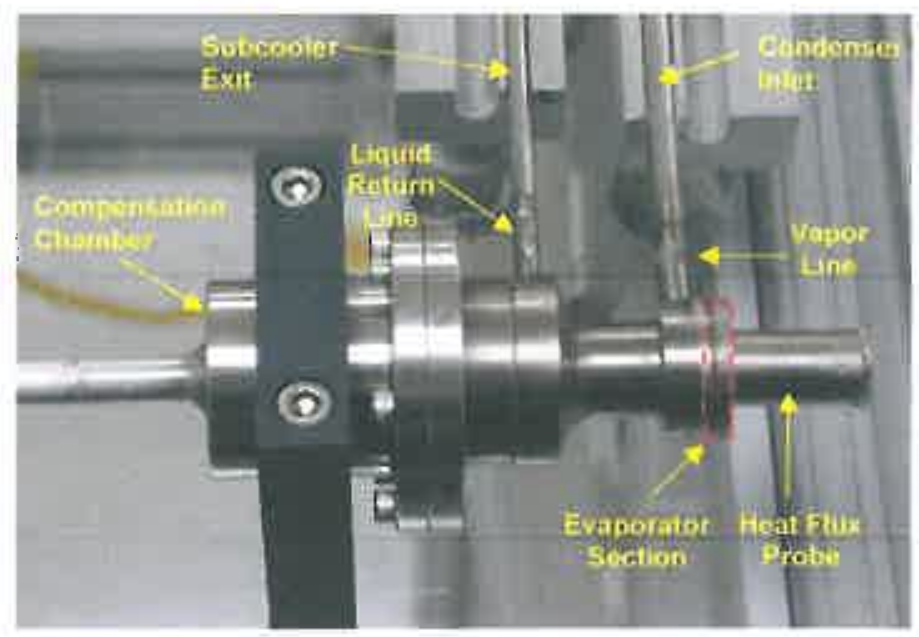

Figure 2. Photo showing close-up of Fractal evaporator integrated into FLHP

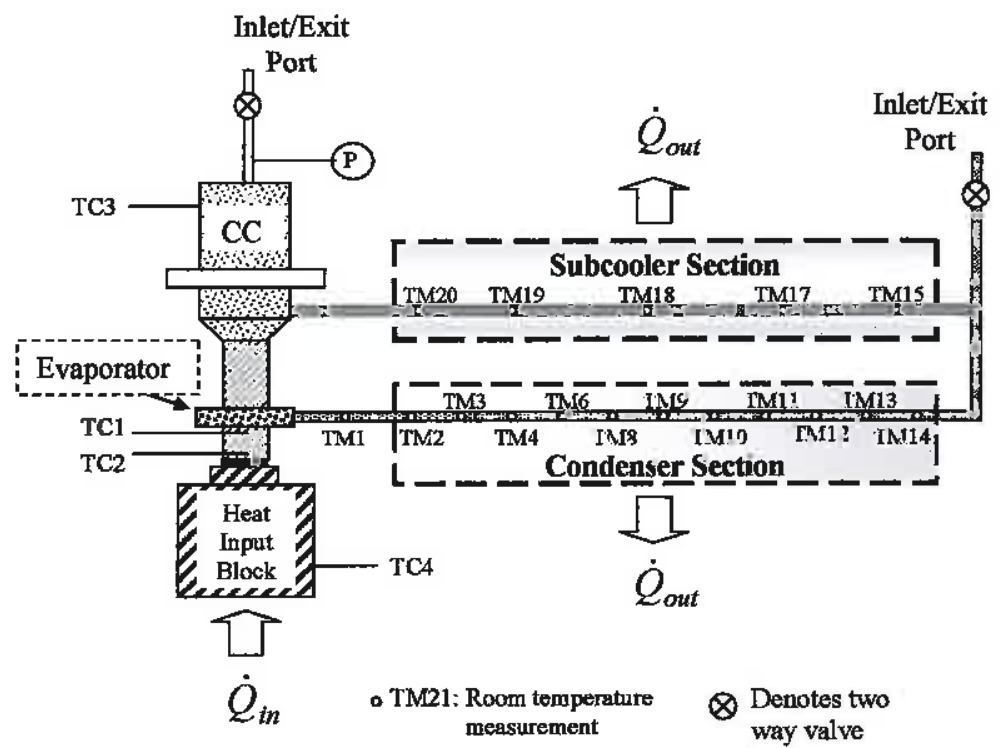

Figure 3. Schematic of the FLHP System

The initial primary and secondary wick structures are shown in Figures $4 \mathrm{a}$ and $4 \mathrm{~b}$. The primary wick structure, as mentioned previously, had an average pore size of 8-10 $\mu \mathrm{m}$ whereas the secondary wick structure had an average pore size of a couple hundred microns. The compressed carbon foam wick structures (shown in Figures $4 \mathrm{c}-4 \mathrm{f}$ ) were made from reticulated vitreous carbon (RVC) Duocel foam which is manufactured by ERG Aerospace, Inc. Duocel foam consists of an open celled reticulated structure with interconnected pores. In its initial state, the carbon foam had an approximate porosity of 10 PPI. The foam was compressed until its average pore size matched that of the primary soda lime glass wick structures. The resultant compressed RVC foam was then machined to feature geometries matching those of the soda lime glass wick structures. For ease of machining the secondary wick structure was separated into two pieces (a cylinder and a cap as shown in Figures $4 \mathrm{~d}$ and $4 \mathrm{e}$ ). When attached to each other (as shown in Figure 4f) the exterior contour of the assembled compressed foam wick matched that of the original soda lime glass secondary wick.

Prior to system testing, the FLHP was evacuated using a roughing pump. Upon completion of the system pump down, the FLHP was then charged with twice distilled, deionized water. Liquid charge volumes for both the silica glass and the compressed foam studies may be found in Table 1. For a detailed description of the charging proce- 

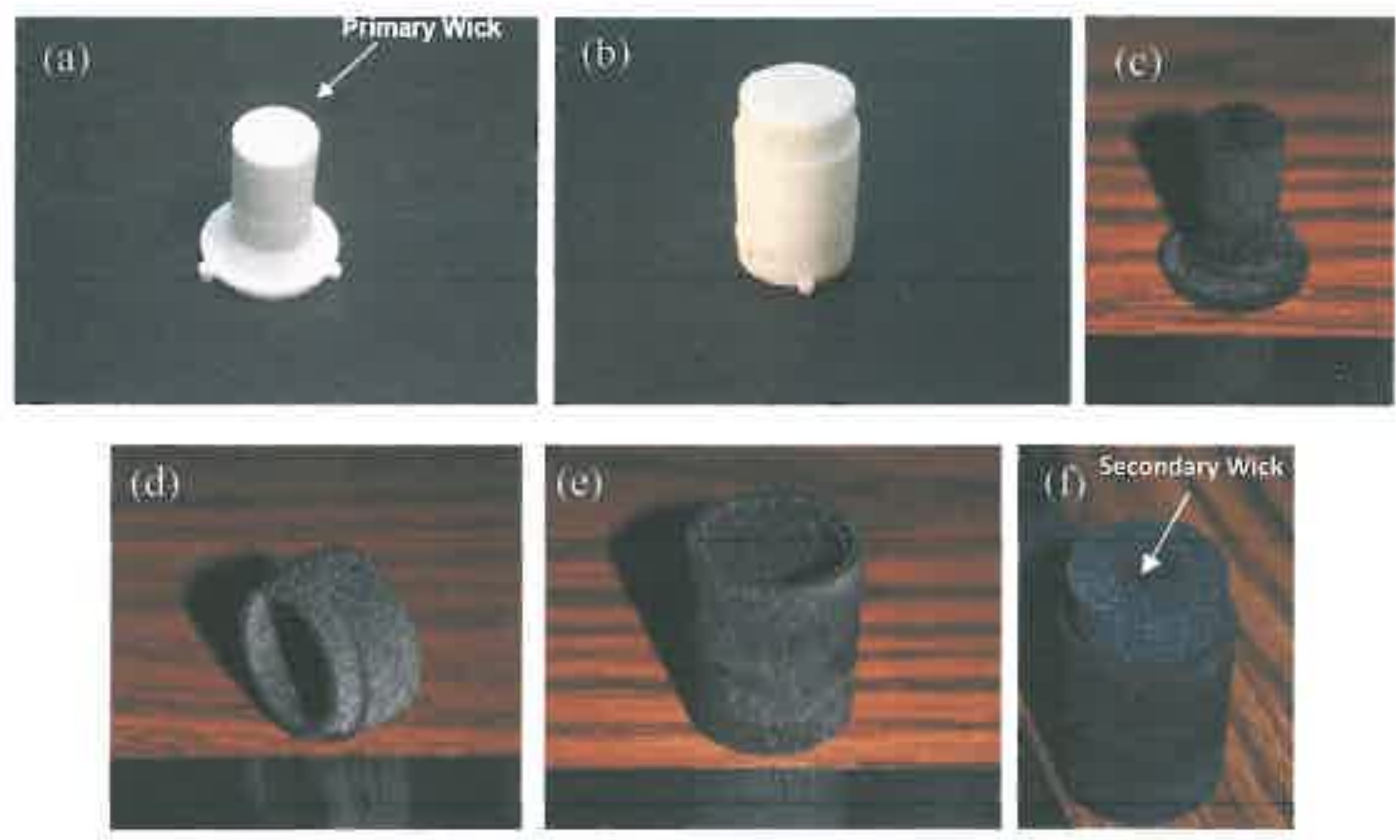

Figure 4. FLHP Wick Structures; (a) Soda Lime Glass Primary Wíck, (b) Soda Lime Glass Secondary Wick, (c) Compressed Carbon Foam Primary Wick, (d) ) Compressed Carbon Foam Secondary Wick Cylinder Cap, (e) Compressed Carbon Foam Secondary Wick Cylinder body, (f) Compressed Carbon Foam Secondary Wick Structure Assembled

dure, see the study by Silk and Myre [28]. Immediately after charging the FLHP, the system's temperature and pressure were measured. Using solubility calculations for air in water the gas concentration in the system was determined. A comprehensive listing of test conditions for the working fluid is shown in Table 1.

Table 1. Saturation conditions at room temperature

\begin{tabular}{|c|c|c|}
\hline \multicolumn{3}{|c|}{ Working Fluid Conditions } \\
\hline & Silica Glass & Compressed Foam \\
\hline Parameters & Degassed Case & Degassed Case \\
\hline $\mathrm{P}_{\text {sat }}$ & $25.3 \mathrm{kPa}$ & $6 \mathrm{kPa}$ \\
\hline${ }^{8} \mathrm{~T}$ & $29^{\circ} \mathrm{C}$ & $23^{\circ} \mathrm{C}$ \\
\hline $\mathrm{h}_{\mathrm{fg}}$ & $2432 \mathrm{~kJ} / \mathrm{kg}$ & $2442 \mathrm{~kJ} / \mathrm{kg}$ \\
\hline Charge level & $30 \mathrm{ml}$ & $32 \mathrm{ml}$ \\
\hline Gas Content & $5 \mathrm{ppm}$ & $1.5 \mathrm{ppm}$ \\
\hline
\end{tabular}

${ }^{\S}$ FLHP equilibrium temperature at $P_{\text {sat }}$ while dormant.

During each test, heat was supplied to the cartridge heater in increments of $10 \mathrm{~W}$ using a programmable power supply. Steady state was achieved at each power level, and data was acquired before application of the next successive heat load Dry-out was detected by a rapid increase in the interface surface's temperature and a rapid decrease in the measured heat flux.

\section{Measurement Uncertainty}

The primary quantities of interest for these experiments are the temperature measurements and the heat flux through the evaporator. The error in the thermistor temperature measurements was $\pm 0.2^{\circ} \mathrm{C}$ whereas for the thermocouples it was $\pm 0.5^{\circ} \mathrm{C}$. The heat flux calculation has three contributions to the uncertainty: the thermal conductivity, the thermocouple locations, and the error in the temperature measured. The thermal conductivity value used was $390 \mathrm{~W} / \mathrm{m}-\mathrm{K}$ with an error of $1 \%$. The error in the evaporator's thermocouple locations was determined to be $\pm 0.1 \mathrm{~mm}$. Equation 1 was used to calculate the error for the heat flux values reported. The maximum uncertainty in the heat flux was determined to be $\left(2.25 \mathrm{~W} / \mathrm{cm}^{2}\right) 3.0 \%$ at $75 \mathrm{~W} / \mathrm{cm}^{2}$ for the Silica glass wick [28] and $\left(2.2 \mathrm{~W} / \mathrm{cm}^{2}\right)$ 
$3.0 \%$ at $72 \mathrm{~W} / \mathrm{cm}^{2}$ for the Carbon foam wick [31]. Standard error analysis (similar to that used for the heat flux calculation) was also performed for the total thermal resistance per unit area (R") of the FLHP. The accuracy of the $R^{\prime \prime}$ calculation improved with increasing heat flux in each of the test cases. The error for the $R^{\prime \prime}$ value was $<0.05$ ${ }^{\circ} \mathrm{C} / \mathrm{W} / \mathrm{cm}^{2}$ at $\mathrm{CHF}$ for each of the test cases. Pressure values had an uncertainty of $\pm 3.1 \mathrm{kPa}$.

$$
\delta \dot{q}^{\prime \prime}= \pm \sqrt{\left(\frac{\partial \dot{q}^{\prime \prime}}{\partial x} \delta_{x}\right)^{2}+\left(\frac{\partial \dot{q}^{\prime \prime}}{\partial k} \delta_{k}\right)^{2}+\left(\frac{\partial \dot{q}^{\prime \prime}}{\partial(\Delta T)} \delta_{\Delta T}\right)^{2}}
$$

\section{Results and Discussion}

\section{A. Heat Flux Performance}

The results shown for the comparative study indicate similar performance trends. Figure 5 is a plot of heat flux versus degree of superheat $\left(T_{i n t}-T_{c c}\right)$ for condenser sink temperature cases of $5^{\circ} \mathrm{C}, 10^{\circ} \mathrm{C}$ and $15^{\circ} \mathrm{C}$. Note that compensation chamber $(\mathrm{CC})$ temperature is used for the superheat reference. Overall, the trend for both wick strictures is tinear. However, the Carbon foam wick cases display less slope (mean slope $1.5 \mathrm{~W} / \mathrm{cm}^{2}{ }^{\circ} \mathrm{C}$ ) indicating

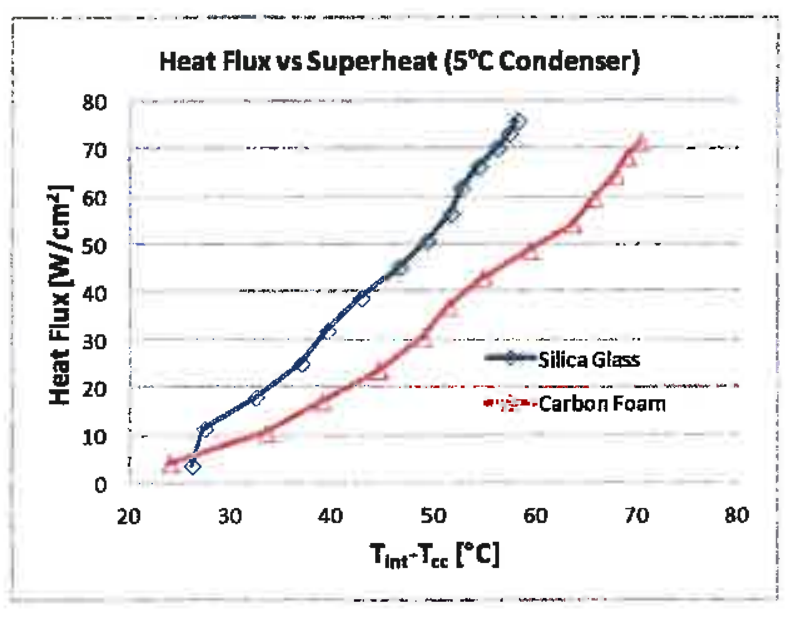

(a)

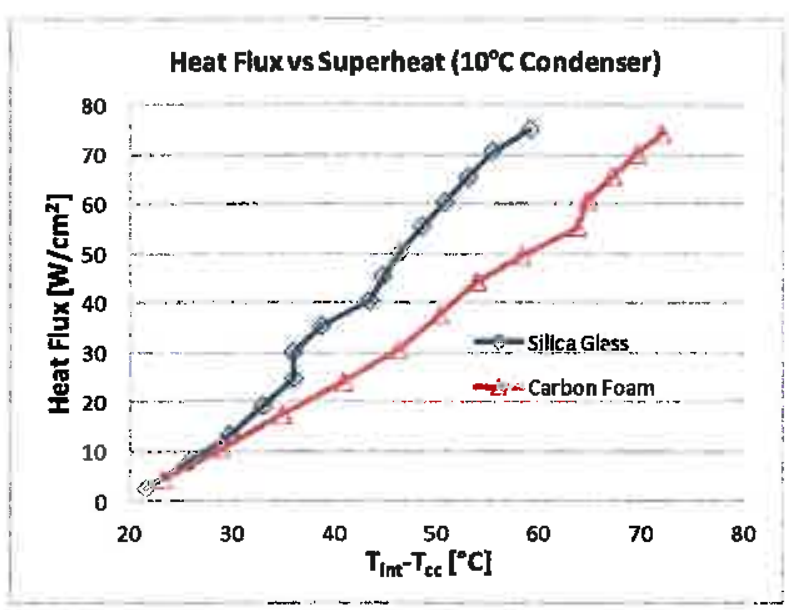

(b)

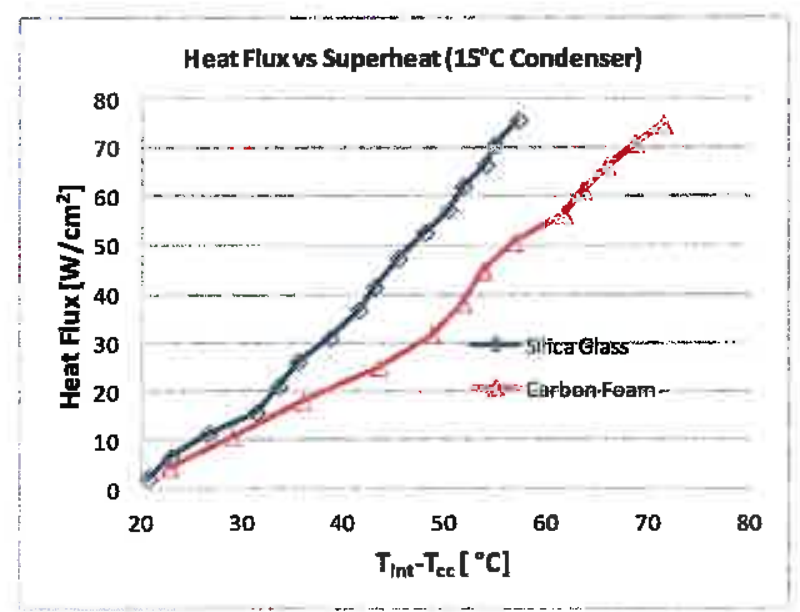

(c)

Figure 5. Comparison of heat flux versus interface temperature for the silica glass and compressed foam wick structures for (a) $5 \mathrm{C}$, (b) $10 \mathrm{C}$ and (c) $15 \mathrm{C}$ sink temperatures. 
more superheat is required to achieve equivalent heat transfer when compared to the silica glass cases (mean slope $2.1 \mathrm{~W} / \mathrm{cm}^{2}{ }^{\circ} \mathrm{C}$ ). In the $5^{\circ} \mathrm{C}$ case the heat flux values diverge beyond a superheat value of $\approx 25^{\circ} \mathrm{C}$ with the silica glass wick case displaying a steeper slope. This results in the silica glass wick case achieving higher heat flux levels relative to the carbon foam wick case at similar superheat values. This is exemplified at the $51.4^{\circ} \mathrm{C}$ superheat level. At this value the silica glass wick achieves $56.3 \mathrm{~W} / \mathrm{cm}^{2}$ while at $51.2^{\circ} \mathrm{C}$ the carbon foam wick achieves $36.8 \mathrm{~W} / \mathrm{cm}^{2}$ heat flux (35\% relative difference).

The slope of the $10^{\circ} \mathrm{C}$ and $15^{\circ} \mathrm{C}$ heat sink are similar to the $5^{\circ} \mathrm{C}$ case in that the Carbon foam slope is 1.4 $\mathrm{W} / \mathrm{cm}^{2}-{ }^{\circ} \mathrm{C}$ for $10^{\circ} \mathrm{C}$ and $1.5 \mathrm{~W} / \mathrm{cm}^{2}-{ }^{\circ} \mathrm{C}$ for $15^{\circ} \mathrm{C}$. The slope of the silica glass wick curve is $2.1 \mathrm{~W} / \mathrm{cm}^{2}-{ }^{\circ} \mathrm{C}$ for the $10^{\circ} \mathrm{C}$ case and $2.0 \mathrm{~W} / \mathrm{cm}^{2}$ for the $15^{\circ} \mathrm{C}$ case. The one difference between the $5^{\circ} \mathrm{C}$ and the other cases (i.e., the $10^{\circ} \mathrm{C}$ and $15^{\circ} \mathrm{C}$ cases $)$ is that at low superheat $\left(<30^{\circ} \mathrm{C}\right)$ the heat flux values are relatively close. This is shown in the $15^{\circ} \mathrm{C}$ where at a superheat of the $22.8^{\circ} \mathrm{C}$ the silica glass wick transfers $6.7 \mathrm{~W} / \mathrm{cm}^{2}$ whereasthe Carbon foam transfers 4.5 $\mathrm{W} / \mathrm{cm}^{2}$. In contrast, at $35.5^{\circ} \mathrm{C}$ the silica glass wick attains $26.3 \mathrm{~W} / \mathrm{cm}^{2}$ whereas the Carbon foam transfers 18 $\mathrm{W} / \mathrm{sm}^{2}$. While the numerical difference is much greater at higher superheat the difference in heat flux for both the low and higher superheat is $33 \%$ and $31.6 \%$ respectively. Using the $10^{\circ} \mathrm{C}$ case as another illustration the heat flux capability of the glass wick at high superheat exceeds that of the foam wick performance such that at $46.4^{\circ} \mathrm{C}$ superheat the silica glass wick transports $50.3 \mathrm{~W} / \mathrm{cm}^{2}$.At a comparable superheat of $46.2^{\circ} \mathrm{C}$, the Carbon foam only transports $30.6 \mathrm{~W} / \mathrm{cm}^{2}$. This is a difference of $39 \%$ relative to the silica glass data. The peak heat flux performance provides a clear illustration of the performance differences. Table 2 is provided to summarize the peak heat flux performance for all three heat sink temperatures tested. The peak heat flux performance for the two wick structures is reasonably close with the silica glass wick achieving higher heat flux over all by $1-6 \%$, but between 21 and $25 \%$ more superheat or an average of $13^{\circ} \mathrm{C}$ more superheat is required to generate the heat flux performance of Carbon foam wick structure.

Table 2. Peak heat flux performance of both wick structures in the FLHP

\begin{tabular}{|c|c|c|c|c|c|}
\hline $\begin{array}{c}\text { Condenser/Subcooler } \\
\text { Temperature }\end{array}$ & Wick Structure & $\begin{array}{l}\text { Superheat } \\
\left({ }^{\circ} \mathrm{C}\right)\end{array}$ & $\begin{array}{c}\% \\
\text { Difference }\end{array}$ & $\begin{array}{c}\text { Heat Flux } \\
\left(W / \mathrm{cm}^{2}\right)\end{array}$ & $\begin{array}{c}\% \\
\text { Difference }\end{array}$ \\
\hline $10^{\circ} \mathrm{C} / 5^{\circ} \mathrm{C}$ & Silica Glass & 57.9 & \multirow[b]{2}{*}{21.1} & 75.8 & \multirow[b]{2}{*}{5.9} \\
\hline $5^{\circ} \mathrm{C} / 5^{\circ} \mathrm{C}$ & Carbon Foam & 70.1 & & 71.3 & \\
\hline $15^{\circ} \mathrm{C} / 10^{\circ} \mathrm{C}$ & Silica Glass & 59.2 & \multirow[b]{2}{*}{21.4} & 75.0 & \multirow{2}{*}{1.2} \\
\hline $10^{\circ} \mathrm{C} / 10^{\circ} \mathrm{C}$ & Carbon Foam & 71.9 & & 74.1 & \\
\hline $20^{\circ} \mathrm{C} / 15^{\circ} \mathrm{C}$ & Silica Glass & 57.2 & \multirow{2}{*}{24.8} & 75.6 & \multirow{2}{*}{1.06} \\
\hline $15^{\circ} \mathrm{C} / 15^{\circ} \mathrm{C}$ & Carbon Foam & 71.4 & & 74.8 & \\
\hline
\end{tabular}

\section{B. Thermal Resistance}

Plots of the thermal resistance versus heat flux are shown in Figure 6 for the $5^{\circ} \mathrm{C}, 10^{\circ} \mathrm{C}$ and $15^{\circ} \mathrm{C}$ condenser temperatures. The thermal resistance is calculated using the interface temperature, the average condenser temperature and the heat flux as shown in Equation 2.

$$
R^{\prime \prime}=\frac{T_{\mathrm{int}}-T_{\text {cond, ovg }}}{\dot{q}^{\prime \prime}}
$$

All plots show a high resistance value at lower heat flux levels and then decay exponentially toward a minimum value for higher heat flux. For all three heat sink temperatures the thermal resistance is higher for the Carbon foam wick. There are a few data points for the $10^{\circ} \mathrm{C}$ and $15^{\circ} \mathrm{C}$ case at low heat flux that are higher than the silica glass wick (e.g. $12.4^{\circ} \mathrm{C} / \mathrm{W} / \mathrm{cm}^{2}$ at $2.5 \mathrm{~W} / \mathrm{cm}^{2}$ versus $10.5^{\circ} \mathrm{C} / \mathrm{W} / \mathrm{cm}^{2}$ at $4.2 \mathrm{~W} / \mathrm{cm}^{2}$ for the Carbon foam with a $10^{\circ} \mathrm{C}$ heat sink temperature). Otherwise, the trend of the data is that the Carbon foam experiences higher thermal resistance across the range of heat flux measured. Since the silica glass case's heat flux is larger than that for the Carbon foam wick and the superheat required to transfer comparable heat flux is lower for the silica glass wick case, based on equation 2 it is clear that the thermal resistance for the silica glass wick should be smaller. Alternatively it requires more superheat for the foam to produce comparable, if slightly lower amounts of heat flux. A discussion overviewing some of the probable causes for this increase in thermal resistance is provided in the following section. 


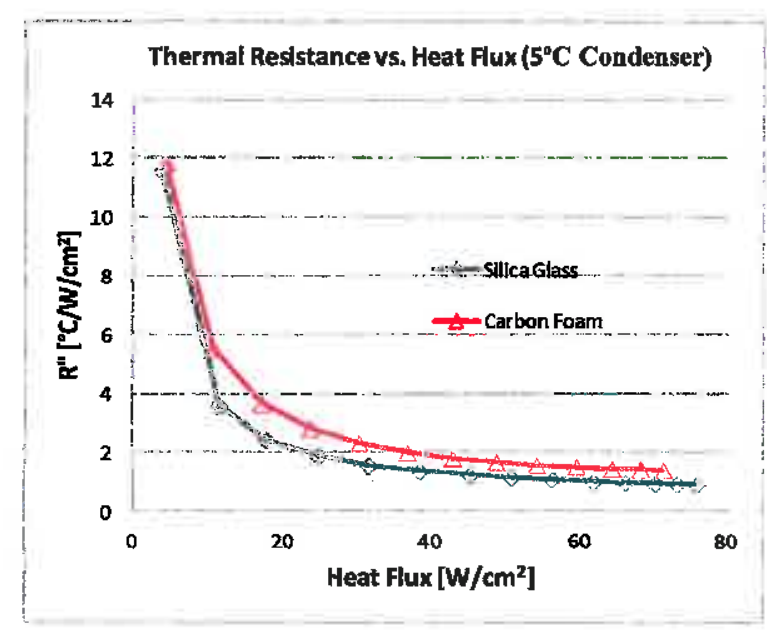

(a)

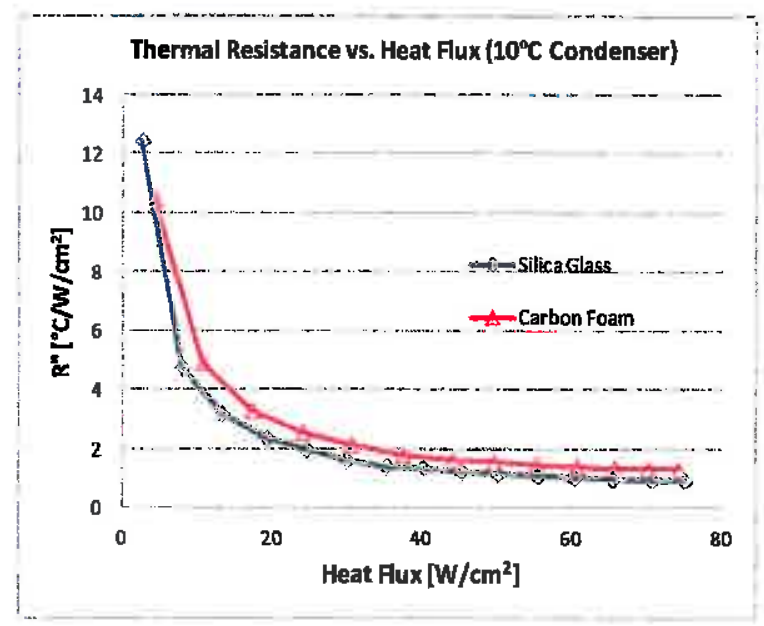

(b)

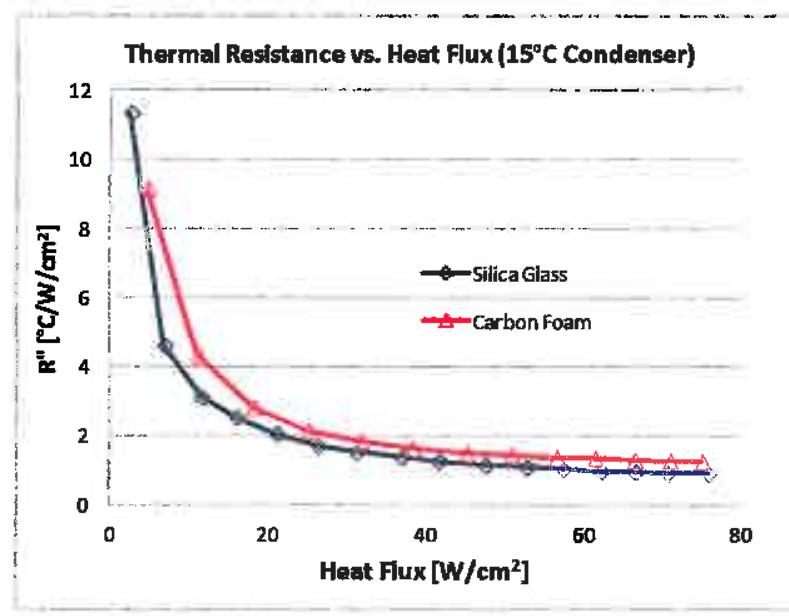

(c)

Figure 6.Comparison of thermal resistance versus heat flux for the silica glass and compressed foam wick structures for (a) $5^{\circ} \mathrm{C}$, (b) $10^{\circ} \mathrm{C}$ and (c) $15^{\circ} \mathrm{C}$ condenser sink temperatures.

\section{Discussion on Performance Differences}

While most aspects of the experimental conditions were maintained constant throughout the FLHP tests, (e.g., the FLHP, the experimental set-up, Fractal evaporator, primary and secondary wick geometry) there were slight differences between the two tests that could be affecting the FLHP performance. While the test conditions for the two cases did not have identical charge levels and gas content, slight differences in non-condensable gases and charge levels are considered to have negligible effect on the test results. The Sink temperatures (i.e. chiller temperatures) were managed differently for the two tests. Two chiller units were used for both tests; one for the "condenser" and one for the "subcooler" (reference Figure 3.) heat exchanger sections. For the silica glass test cases the chiller temperatures were offset by $5^{\circ} \mathrm{C}$ with the subcooler section having a lower setpoint than the condenser section (shown in Table 2.).. . For the Carbon foam tests both chillers were operated at the same setpoints (i.e., $5^{\circ} \mathrm{C}$, $10^{\circ} \mathrm{C}$ and $15^{\circ} \mathrm{C}$ on the condenser and subcooler). This arrangement would seem to give an overall thermodynamic advantage to the Carbon foam structure. Yet the heat flux performance is slightly less and the superheat required to produce nearly equivalent heat flux (to the silica glass case) performance is much higher. 
Additional differences involve the wick structures themselves. Due to challenges experienced during the machining of the foam, the final secondary wick consisted of two pieces. This created two internal flow interfaces as opposed to one (which was the case for the silica glass wick structure). Also, the Carbon foam secondary wick has a different porosity (smaller) than the silica glass secondary wick. Hence, from a standpoint of hydrodynamic performance, the Carbon wick has a more arduous flow path because of the smaller pores in the secondary wick and the one additional (two total) flow interface. Since the secondary wick receives liquid from the compensation chamber and must feed the primary wick, the difference in porosity and increased fluid interfaces may have reduced the rate of supply of working fluid to the evaporator in the Carbon foam wick. This situation is not as severe at low superheat levels, but is pronounced at moderate to high superheat $\left(>30^{\circ} \mathrm{C}\right)$. An additional difference is the actual pore geometries in the two wick structures. Sintered wicks form pores by virtue of the fusion of silica glass bead material. This is similar to a sintered metal configuration in other common LHP wick structures. The open celled reticulated structure with interconnected pores created by the foam ligaments creates "pores" in the Carbon foam wick which are different than the pore structures formed in sintered wicks (Silk and Myre [30]). The impact on flow impedance and heat transfer should be studied further. Last but not least, another difference between the wick structures is the heat leak that may be present during testing. Carbon is generally considered highly conductive. However, ERG reports their thermal conductivity values as a fraction $(0.033-0.050 \mathrm{~W} / \mathrm{m}-\mathrm{K})$ [31] of that of silica glass $(\approx 1.4 \mathrm{~W} / \mathrm{m}-\mathrm{K})[32$. The wick material conduction ratio ranges between $28-42: 1$ indicating the opportunity for heat leak is most likely to occur in the silica glass wick tests. One of the implied performance aspects of the FLHP is the use of low conductivity wick structures [34]. The test data indicates both wick structures perform well. Whenexamining the trends for each wick throughout the test duration, as well as the compensation chamber temperatures, there are no clear trends evident between the two wick tests that would indicate one or the other is uncergoing more or less heat leak.

\section{Conclusions and Future Work}

AnFLHP test bed was used to compare two wick materials (silica glass and Carbon foam) with identical primary and secondary wick geometry. Heat flux and thermal resistance were determined from thermocouple and thermistor data recorded via data acquisition during testing. The original silica glass wick and compressed carbon foam wick have comparable heat flux and thermal resistanceperformance. However, the comprehensive heat flux periormance was somewhat better for the silica glass wick structure. This is exemplified in the noticeable increase in superheat neededto achieve the maximum heat flux for each of the Carbon foam wick tests. While peak heat trarsfer was a maximum of $6 \%$ higher $\left(5^{\circ} \mathrm{C}\right.$ case) for the silica glass wick the superheat was as much as $25 \%$ higher $\left(15^{\circ} \mathrm{C}\right.$ case) for the Carbon foam wick. When examining the thermal resistance results a similar trend is apparent. The thermal resistance is higher for the Carbon foam cases. At high heat flux values the difference in thermal resistance is close to $50 \%\left(5^{\circ} \mathrm{C}\right.$ case). This increased thermal resistance for the Carbon foam wick was likely due to flow impedance resulting from the additional flow interface and differences in porosity between the two secondary wick structures. Nonetheless, the heat transfer performance for the Carbon foam wick is comparable. The use of compressed foam reduces the challenges inherent to the fabrication of a given wick geometry to machining techniques. In light of this fact, compressed foam could be used in many LHP (as well as heat pipe) applications. The efficacy of the compressed carbon foam wick is strongly indicated and warrants further study.

\section{Disclaimer}

The ideas and opinions expressed in this document are solely those of the authors' and do not represent official NASA policy.

\section{Acknowledgments}

David Myre was supported by the United States Naval Academy's Aerospace Engineering Department during the conduct of these experiments and is now a consultant for KDM Systems, Inc. of Chantilly Virginia. Eric Silk was supported by the Cryogenics and Fluids Branch at the NASA Goddard Space Flight Center. Special thanks to Brandon and William Stanley for their efforts and consultation in the machining of the compressed foam wick struiture used in this study. Special thanks also go to Mark McClendon and NASA Goddard Space Flight Center's Materials Engineering Branch (Code 541) for their support in providing SEM photos of the silica glass wick structure. Last but not least, thanks to ERG Aerospace for providing SEM photos of their compressed foam structures. 


\section{References}

${ }^{1} \mathrm{Ku}$, J., "Operating Characteristics of Loop Heat Pipes," $29^{\text {th }}$ International Conference on Environmental Systems, Society of Automotive Engineers, July 12-15, Denver, Colorado, 1999

${ }^{2} \mathrm{Ku}$, J., "High Frequency Low Amplitude Temperature Oscillations in Loop Heat Pipe Operation," $33^{r d}$ International Conference on Environmental Systems, Society of Automotive Engineers, July 7-10, Vancouver, British Columbia, Canada, 2003

${ }^{3} \mathrm{Ku}$, J. and Rodriguez, J., "Low Frequency High Amplitude Temperature Oscillations in Loop Heat Pipe

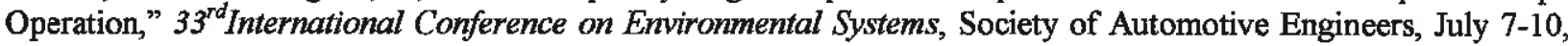
Vancouver, British Columbia, Canada, 2003

${ }^{4}$ Kaya, T. and $\mathrm{Ku}, \mathrm{J}$. , "Thermal Operational Characteristics of a Small-Loop Heat Pipe," AIAA Journal of Thermophysics and Heat Transfer, Vol. 17, No. 4., 2003, pp. 464-470

${ }^{5}$ Hongxing, Z., Guiping, L., Ting, D., Wei, Y., Xingguo, S., Sudakov, R. and Maidanik, Y., "Investigation of Startup Behaviors of a Loop Heat Pipe," AIAA Journal of Thermophysics and Heat Transfer, Vol, 19, No. 4,, 2005, pp. 509-518

${ }^{6}$ Guiping, L., Hongxing, Z., Xingguo, S., Jianfeng, C., Ting, D. and Jianyin, M., "Investigation of Effects of Auxiliary Measure for Startup of Loop Heat Pipes," AIAA Journal of Thermophysics and Heat Transfer, Vol. 20, No. 3., 2006, pp. 389-397

${ }^{7}$ Riehl, R, and Siqueira, T., "Heat transport capability and compensation chamber influence in loop heat pipes performance," Applied Thermal Engineering, Vol. 26, 2006, pp. 1158-1168

${ }^{8}$ Singh, R., Akbarzadeh, A, Dixon, C. and Masataka, M., "Novel Design of a Miniature Loop Heat Pipe Evaporator for Electronic Cooling," ASME Journal of Heat Transfer, Vol. 129, 2007, pp. 1445-1452

${ }^{9}$ Vershinin, $S$. and Maydanik, $Y_{r}$ "Investigation of pulsations of the operating temperature in a miniature loop heat pipe," International Journal of Heat and Mass Transfer, Vol. 50, 2007, pp. 5232-5240

${ }^{10}$ Chernysheva, M.A., Vershinin, S.V. and Maydanik, Y.F., "Operating temperature and distribution of a working fluid in LHP," International Journal of Heat and Mass Transfer, Vol. 50, 2007, pp. 2704-2713

${ }^{11}$ Vershinin, S. and Maidanik, $Y_{\circ}$ "Hysteresis phenomena in loop heat pipes," Applied Thermal Engineering, Vol. 27, 2007, pp. $962-968$

${ }^{12}$ Hoang, T.T. and Kaya, T., "Mathematical modeling of loop heat pipes with two-phase pressure drop," AIAA's $33^{\mathrm{rJ}}$ Thermophysics Conference, June 28 - July 1, Norfolk, VA., 1999

${ }^{13}$ Hamdan, M., Cytrynowicz, D., Medis, P., Shuja, A., Gerner, F., Henderson, H., Golliher, E., Mellott, K. and Moore, C., "Loop Heat Pipe (LHP) Development by Utilizing Coherent Porous Silicon (CPS) Wicks," ITHERM $20028^{\text {th }}$ Inter Society Conference on Thermal Phenomena, May 30-June 1, San Diego, CA, 2002

${ }^{14} \mathrm{Ren}, \mathrm{C}$, Wu, Q-S. and Hu, M-B., "Heat transfer with flow and evaporation in loop heat pipe's wick at low or moderate heat fluxes," International Journal of Heat and Mass Transfer, Vol. 50, 2007, pp. 2296-2308

${ }^{15}$ Ren, C. and Wu, Q-S., "Heat Transfer in Loop Heat Pipes Capillary Wick: Effect Effective Thermal Conductivity", AIAA Journal of Thermophysics and Heat Transfer, Vol. 21, No. 1., 2007, pp. 134-140

${ }^{16}$ Pauken, M., Birur, G., Nikitkin, M., Novak, K and Al-Khabbaz, F., "Thermal Performance Evaluation of a

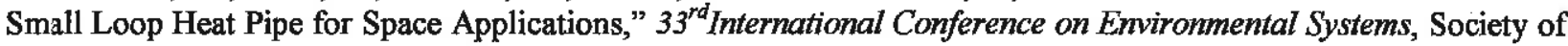
Automotive Engineers, July 7-10, Vancouver, British Columbia, Canada, 2003

${ }^{17}$ Birur, G., Johnson, K., Novak, K. and Sur, T., "Thermal Control of Mars Lander and Rover Batteries and Electronics Using Loop Heat Pipe and Phase Change Material Thermal Storage Technologies," $30^{\text {th }}$ International Conference on Environmental Systems, Society of Automotive Engineers, Dates, July 10-13, Toulouse, France, 2000

${ }^{18}$ Maidanik, Y., "Loop heat pipes," Applied Thermal Engineering, Vol. 25, 2005, pp. 635-657

${ }^{19}$ Launay, S., Sartre, V. and Bonjour, J., "Parametric analysis of loop heat pipe operation: a literature review," International Journal of Thermal Sciences, Vol. 46, 2007, pp. 621-636

${ }^{20}$ Zinna, S., Vasiliev, L., Marengo, M. and Ferrandi, C., 2009, "Advanced Design of A Low Cost Loop Heat Pipe and Comparison With A Novel Numerical Approach," $41^{s t}$ ALAA Thermophysics Conference, June 22-25, San Antonio, Texas, USA

${ }^{21}$ Hartenstine, J.R., Anderson, W.G., and Bonner, R., "Titanium Loop Heat Pipes for Space Nuclear Power Systems," in proceedings of Space Technology and Applications International Forum (STAIF-08), edited by M S. El-Genk, pp. 44-52, American Institute of Physics, Melville, New York, 2008. 
${ }^{22} \mathrm{Ku}$, J, Ottenstein, L., Douglas, D, Pauken, M, Birur, G., 2005, "Miniature Loop Heat Pipe with Multiple Evaporators for Thermal Control of Small Spacecraft," Government Microcircuit Applications and Critical Technology Conference, April 4-7, Las Vegas, Nevada

${ }^{23}$ Hoang, TT, O'Connell, T, Khrustalev, D., 2003, "Development of a Flexible Advanced Loop Heat Pipe for Across Gimbal Cryocooling", SPIE 1Ith Cryogenic Optical Systems and Instruments, proceedings vol. 5172

${ }^{24}$ Hoang, TT, O'Connell, T, Ku, J, Butler, D., Swanson, T, 2003, "Large Area Cryocooling for Far Infrared Telescopes," SPIE $11^{\text {th }}$ Cryogenic Optical Systems and Instruments, proceedings vol. 5172

${ }^{25}$ Wu, S-C., Hsieh, B-H., Yeh, C-C. and Chen, Y-M., 2009, "Investigation of the Polymer Wick Structure Applied to Loop Heat Pipe," $4^{\text {th }}$ International Conference on Microsystems, Packaging, Assembly and Circuits Technology, October 21-23, Taipei, Taiwan, IEEE proceedings pp. 368-371

${ }^{26}$ Nagano, H., Fukuyoshi, F., Ogawa, H. and Nagai, H., 2010, "Development of An Experimental Small Loop Heat Pipe with PTFE Wick," $40^{\text {th }}$ International Conference on Environmental Systems, July 11-15, Barcelona, Spain

${ }^{27}$ Valenzuela, J., Capillary Evaporator, U.S. Patent Number 6,863,117, 2005

${ }^{28}$ Silk, E.A. and Myre, D., 2009, "Fractal Loop Heat Pipe Heat Flux and Operational Performance Testing," 2009 ASME Summer Heat Transfer Conference, July 19-23, San Francisco, CA., USA

${ }^{29}$ Silk, E.A. and Myre, D., 2010, "Investigation of Gravitational Effects On Fractal Loop Heat Pipe Performance," $48^{\text {th }}$ AIAA Aerospace Sciences Meeting, Jan. 4-7, Orlando, Fl, USA

${ }^{30}$ Silk, E.A. and Myre, D.D., "Fractal Loop Heat Pipe Performance Testing With A Compressed Carbon Foam Wick Structure", Applied Thermal Engineering, Available online 31 May 2013, ISSN 1359-4311.

${ }^{31} \mathrm{http}: / /$ ergaerospace.com/RVC-properties.htm

${ }^{32}$ Introduction to Heat Transfer, Incropera, F.P.,DeWitt, D.P., John Wiley \& Sons, Inc., 2002 